\title{
Predicting the Integrity of Existing Prestressed Concrete Bridge Deck Using Sonic Method
}

Ming-Te Liang

Professor, Department of Harbor and River Engineering, National Taiwan Ocean University, Keelung, Taiwan, R.O.C.

Jyi Wu

Postgraduate, Department of Harbor and River Engineering, National Taiwan Ocean University, Keelung, Taiwan, R.O.C.

Follow this and additional works at: https://jmstt.ntou.edu.tw/journal

Part of the Civil and Environmental Engineering Commons

\section{Recommended Citation}

Liang, Ming-Te and Wu, Jyi (2001) "Predicting the Integrity of Existing Prestressed Concrete Bridge Deck Using Sonic Method," Journal of Marine Science and Technology. Vol. 9: Iss. 1, Article 6.

DOI: $10.51400 / 2709-6998.2434$

Available at: https://jmstt.ntou.edu.tw/journal/vol9/iss1/6

This Research Article is brought to you for free and open access by Journal of Marine Science and Technology. It has been accepted for inclusion in Journal of Marine Science and Technology by an authorized editor of Journal of Marine Science and Technology. 


\title{
PREDICTING THE INTEGRITY OF EXISTING PRESTRESSED CONCRETE BRIDGE DECK USING SONIC METHOD
}

\author{
Ming-Te Liang* and Jyi $\mathrm{Wu}^{* *}$
}

Keywords: corrosion damage, integrity evaluation, reflection coefficient, sonic wave.

\section{ABSTRACT}

The principal objective of this paper was provided a general idea for predicting the integrity of existing prestressed concrete bridge decks by using sonic method. The governing equation is a onedimensional wave equation with initial conditions. The method of Fourier transform was adopted for seeking D'Alembert's solution which is an analytical solution of the governing equation. Furthermore, the wave formulae such as displacement, velocity, force and stress waves were derived from the analytical solution. If the viscosity effect of material was neglected, then the elastic wave can be reduced as the sonic wave. Through these sonic wave formulae, the damage position of the existing prestressed concrete bridge deck may be predicted by using the sonic testing method. The predicted results can be offered as a basis of repair, reinforcement and demolition in service. The results of the present conception indicate that the sonic method may be really to predict the cracked position of the existing prestressed concrete bridge decks and the position of corrosion or failure of steel tendon. The advantage of the sonic method may be not only portable but also convenient.

\section{INTRODUCTION}

At present, the big-type trucks with heavy weight are fast developed. The traffic flow on bridge is continuously increased. Moreover, the environmental factors such as $\mathrm{CO}_{2}, \mathrm{Cl}^{-}$and $\mathrm{SO}_{2}$ are penetrated into concrete. These factors result in concrete cracks and spalling and failure of steel tendon in prestressed concrete bridges due to corrosion. The study of predicting the damage position of the prestressed concrete bridges is caused as a very important subject. Especially, the inspection of prestressed concrete bridge deck is not so easy to be detected. In addition, owing to both the hammering testing and X-ray photo methods can not be adopted to

Paper Received July 28, 2000. Author for Correspondence: Ming-Te Liang. *Professor, Department of Harbor and River Engineering, National Taiwan Ocean University, Keelung, Taiwan, R.O.C.

**Postgraduate, Department of Harbor and River Engineering, National Taiwan Ocean University, Keelung, Taiwan, R.O.C. predict the actual damage position of the prestressed concrete bridge decks, a new testing method or suitable method is now necessary to develop.

During the currently established many diagnostic methods, the technique development of non-destructive testing has been fast carried out. In the future, this technique will be of trend of a necessary method for structural quality. In the case of the property of tested material, the ultrasonic testing, eddy current testing and $\mathrm{X}$-ray methods are all set up following the development of steel structures. Since these methods can subjectively estimate the metal quality, the major usage is to predict a local damage. The additional method is to predict a little crack due to fatigue or over loading. In the field of concrete structures, the method of nondestructive testing has some breakthroughs such as predict the internal damage in reinforced concrete structures, determine the steel length, examine the internal inclusion in prestressed concrete structures, and detect the crack of corrosion steel. If compared the development of nondestructive testing in the field of concrete structures with testing of steel structure, the nondestructive testing applied to concrete structures is really fallen behind [Akasrii,1998].

When some prestressed concrete bridges with damages were continuously removed, replaced, repaired and reinforced [Sugimoto, 1995], the damage problem of bridge deck was called attention in the following quality problem of concrete bridges. In the damage detection for the general structures, both the X-ray and Schmidt or rebound hammer methods are usually adopted. However, both of them are very difficult for predicting the local damage of bridge decks. For example, as regards the testing of reinforcing material inclusion, the current X-ray method [Han and Wang, 1992] can only predict the transmitted distance about $40 \mathrm{~cm}$. Moreover, besides the tested side, the similar step should be done again the opposite side of the object. The safe problem of the X-ray method used in city has to consider. One of the limitation factors is economy and heavy apparatus. At present, the systems of radar and instrument of the X-ray method have been 
improved such as the heavy apparatus has been needed to be reduced. But the X-ray method can used to predict both concrete and foundation till now. As to the bridge deck with long distance measurement, the testing technique can not be established. This is quite different from treating the cracks of both steel and concrete structures. Many testing methods could be performed each other. Moreover, both the loading test and vibration test on the bridge deck are used to predict the overall structural system. The evaluation of serviceable structural system is usually estimated after measuring the structural size. However, most of situations, the measure results can not obtained from the direct measure apparatus. As to the other modern development testing methods such as infrared thermography, the damage position can be only predicted under the relative surface temperature in the destination range. It is physically obvious that the infrared thermography is depended on the factors of weather, atmosphere, temperature and other environment. As a result, the objectivity and time become the major factor of development limitation of the infrared thermography.

The main purpose of this paper was offered a concept for predicting the integrity of prestressed concrete bridge decks using the sonic method. The result of this study may be provided the damage position for repair and reinforcemant to the prestresseed concrete bridge decks.

\section{INFLUENCE OF CORROSION DAMAGE}

When the bridge deck has been suffered damage, the performance of serviceability is correspondently decaied. The principal factor is environment in addition to the influence of repeated loading of big-type trucks with heavy weight and lots of traffic flow. When $\mathrm{CO}_{2}$, $\mathrm{Cl}^{-}$and $\mathrm{SO}_{2}$ penetrate into concrete of bridge decks, the corrosion damage will be occurred. The structural kinds of corrosion influence consist of prestressed concrete structures besides ordinary reinforced concrete structures. In the light of prestressed high strength steel tendon in prestressed concrete, the working stress is higher than that of the ordinary reinforced concrete. This is resulted from the prestressed concrete with a small cross-sectional area. Hence, when the prestressed high strength steel is undergone corrosion influence, the corrosion damage is higher than that of the ordinary reinforced concrete [Zhao, 1996]. Generally speaking, this will result in three failure modes to bridge decks of prestressed concrete. Now we describe them in the following:

\section{(1) pitting corrosion}

The pitting corrosion of steel tendon in prestressed concrete is called by electrochemisty as the same process of steel in oridinary reinforced concrete [Treadaway, 1988]. In the case of the prestressed concrete, the pitting corrosion is more danger than that of general (uniform) corrosion. The pitting corrosion results from the phenominon of stress concentration. This will severely reduce the durability and fatigue strength.

\section{(2) stress corrosion}

Stress-corrosion cracking refers to cracking caused by the simultaneous presence of tensile stress and a specific corrosion medium [Jones, 1996]. The important variable affecting stress-corrosion cracking are temperature, solution composition, metal composition, stress, and metal structure.

\section{(3) hydrogen embrittlement}

Treadaway [1988] pointed out that two major effects of reinforcement corrosion are observed: The development of cracking and spalling as a result of tensile force produced as corrosion product, which occupies a greater volume than the parent metal, is formed; and reduction in the cross-sectional area of the metal as corrosion proceeds. The former process is likely to be dominant in relation to ordinary reinforced concrete while the latter is likely predominate in prestressed concrete. Special cases of stress corrosion cracking and hydrogen embrittlement have also been reported as loading to damage in prestressed concrete construction but since this present document confines its attention to ordinary reinforced concrete coustruction no further reference to prestressed concrete construction will be made.

Hydrogen embrittlement is an important bed influence due to cathodic protection for the mitigation of corrosion of steel or metals [Hong, 1998]. The mechanical properties, especial the durability and fatigue strength of steel, of the prestressed steel tendon will be changed by hydrogen embrittlement [Jones, 1996]. Owing to the high strength steel adopted in the prestressed concrete structures, there are some phenomena happen such as V-shaped notch occurred from heat treatment or bed mechanical process, defect come from corrosion and reduction of strain rate. The reaction of dissolved hydrogen is possibly occurred when the potential of steel with high strength is more less than saturated calomel electrode $(-900 \mathrm{mV})$. The hydrogen atoms dissolved from the dissolved hydrogen will osmosize in steel to product hydrogen molecule. Moreover, the tension happening results in steel brittle. Finally, the steel is caused to happen failure. On the other hand, the steel with low strength used in the 
ordinary reinforced concrete is not sensible with respective to hydrogen embrittlement. The protential happened possibly failure due to hydrogen embrittlenent is less than $-1100 \mathrm{mV}$. Generally speaking, the fixed reference electrode was embedded on the some specific measure points. The situation of potential distribution of steel can not be complelely overall response. Some regions are in fact occurred over protection. Thus, the danger due to over protection will be happened. As to the concrete adopted steel with high strength, how to control severely cathotic protection can be avoided the happening of hydrogen embrittlemtent due to over protection. From occasions adopted the method of electrochemisty are safe. They are described as follows:

1. Use steel protector. Both the steel protector and the other ordinary steels have big shield action of concrete flow to prestressed steel tendon. 2. The cover thickness of concrete for steel protector is larger than that of ordinary steel at the region for treatment. 3 . The prestressed steel tendon is a kind of cold-rolled steel without the constituent of chromic alloy. The coldrolled steel has no sensitivity to the permanent hydrogen embrittlement. The hydrogen osmosized into the prestressed steel tendon will effusion out after unloading. Thus, the prestressed steel tendon will be not happened failure. 4. The electrochemical process can be carried out after the prestressed steel tendon is unloaded. Under the condition of no steel protector and not enough cover thickness, the treatment of electrochemistry for prestressed steel tendon should be performed that the surface potential on steel unloaded and severe control does not reach the dissolved potential.

\section{DERIVATION FOR DAMAGE POSITION FORMULAS FOR PRESTRESSED CONCRETE DECKS}

\section{Measurement principle}

Until now, the application of sonic principle to nondestructive testing has not enough measurement technique. The in-situ structure is actually larger than the model test in laboratory. Furthermore, the problem of environmental factors is really tough in addition to material factor.

At present, the sonic method is usually used to survey and study the pile length and damage. This is socalled a method of sonic integrity testing. Generally speaking, the sonic method used in laboratory is put the transmitter and receiver on the both side of tested specimen The transmitter occurs sonic wave in terms of piezoelectricity effect. Since the length of tested specimen can be measured. The sonic apparatus shows automatically time. Thus, the wave velocity can be calculated. However, on the study of pile length and damage, the pile should be longitudinally cored two hole for transmitter and receiver for doing test. We may adopt the stress wave due to impact to do nondestructive testing for pile. In a general sense, the method of stress wave due to impact is more economic than that of the sonic method. Since the prestressed concrete in a nonuniform and porous material, the sound wave propagated in concrete has loss energy. In addition to that, the wave with higher frequency is of high sensitivity. It can probe a small crack. However, the wave with lower frequency has large wave length. It can not detect a small crack. As the material size of the prestressed concrete bridge deck is large, the sonic method with lower frequency can be adopted for doing nondestructive testing.

\section{Wave theory}

Suppose that the prestressed concrete deck is a uniform, isotropic, nonviscous and elastic material. Condiser the one-dimensional wave equation with intial conditions [Kreyszig, 1999]

$$
\begin{aligned}
& \frac{\partial^{2} u}{\partial t^{2}}=c^{2} \frac{\partial^{2} u}{\partial x^{2}} \quad u(x, 0)=\bar{f}(x), \quad \frac{\partial u(x, 0)}{\partial t}=\bar{g}(x), \\
& -\infty<x<\infty
\end{aligned}
$$

where $u$ is displacement, $x$ is space, $t$ is time, $c$ is wave velocity, $\bar{f}(x)$ and $\bar{g}(x)$ are the initial displacement and velocity of particle, respectively.

As we know that the compressed zone length is ct after time $t$. If the prestressed concrete deck is originally stationary and the end face is caused to move with, and maintains uniform particle velocity $v$, the whole length will be moving with $v$ at time $t$. Equating the change in momentum of this length ct to the impulse, gives

$$
\sigma=\rho c v
$$

where $\sigma=\frac{F}{A}$ is the stress of the prestressed concrete deck, $F, A$ and $\rho$ are the strength, cross-sectional area and density of the prestressed concrete deck, respectively, $v$ is the particle velocity and $\rho c$ is the mechanical impedance.

Since the end at which impact occurs will have moved through distance vt, the strain in the compressed zone is $\varepsilon=\frac{v t}{c t}=\frac{v}{c}$ and thus $\sigma=E \varepsilon=E \frac{v}{c}$. Substituting in Eq. (2) for $\stackrel{c t}{\sigma}$ gives

$c=\sqrt{\frac{E}{\rho}}$

Combining Eqs. (2) and (3) yields force at distance 
and time $t$

$$
F(x, t)=\frac{E A}{c} v(x, t)=Z v(x, t)
$$

where $Z=\frac{E A}{c}$ is the impedance (dynamic stiffness) of the prestressed concrete deck.

Taking the Fourier transform first and then the inverse Fourier transform to Eq. (1), we obtain the solution [Kreyszig, 1999]

$$
u(x, t)=\frac{1}{2}[f \uparrow(x+c t)+f \downarrow(x-c t)]+\frac{1}{2 c} \int_{x-c t}^{x+c t} g(\xi) d \xi
$$
becomes

If the initial condition $\frac{\partial u}{\partial t}=\bar{g}(x)=0$, then Eq (5)

$$
u(x, t)=\frac{1}{2}[f \uparrow(x+c t)+f \downarrow(x-c t) \cong u \uparrow+u \downarrow
$$

Based on Eq. (6), the formaulas of velocity, force and stress wave propagation are obtained as follows [Liang, 1986]:

$$
\begin{aligned}
& v=\frac{d u}{d t} \cong v \uparrow+v \downarrow \\
& F=\frac{E A}{c} v=-E A \frac{d u}{d x} \cong F \uparrow+F \downarrow \\
& \sigma=-E \frac{d u}{d x} v \cong \sigma \uparrow+\sigma \downarrow
\end{aligned}
$$

where $v \uparrow=c u^{\prime} \uparrow, v \downarrow=-c u^{\prime} \downarrow, F \uparrow=-E A u^{\prime} \uparrow, F \downarrow=$ $-E A u^{\prime} \downarrow, \sigma \uparrow=-E u^{\prime} \uparrow=-\rho c v \uparrow$ and $\sigma \downarrow=-E u^{\prime} \downarrow=\rho c v$ $\downarrow$.

Using the sonic method for predicting the integrity of prestressed concrete deck, when impact a force (or use transmitter) on deck, one wave propagates downward $(\downarrow)$, the other waves propagate upward $(\uparrow)$. The wave velocity propagated in deck is $c=\sqrt{\frac{E}{\rho}}$. In addition, the relationships between particle velocity and force at space $x$ and time $t$ are

$$
\begin{aligned}
& v \downarrow(x, t)=\frac{F \downarrow(x, t)}{Z} \\
& v \uparrow(x, t)=\frac{F \uparrow(x, t)}{Z}
\end{aligned}
$$

Based on Eqs. (7) and (8) and and $\mathrm{F}$ are continuous, the relative formulas of and $\mathrm{F}$ at discontinuous position $x_{1}, x_{2}$ and time $t_{1}, t_{2}$ can be expressed as

$$
\begin{aligned}
& v_{1} \downarrow+v_{1} \uparrow=v_{2} \downarrow+v_{2} \uparrow \\
& F=Z_{1}\left(v_{1} \downarrow-v_{1} \uparrow\right)=Z_{2}\left(v_{2} \downarrow-v_{2} \uparrow\right) \\
& v_{2} \downarrow=\frac{Z_{1}}{Z_{2}}\left(v_{1} \downarrow-v_{1} \uparrow\right)+v_{2} \uparrow
\end{aligned}
$$

Let the reflection coefficient be

$$
r_{1}=\frac{Z_{1}-Z_{2}}{Z_{1}+Z_{2}}
$$

where $Z_{1}$ and $Z_{2}$ stand for the upward and downward impedance, respectively. From Eqs. (12), (14) and (15), we obtain

$$
\begin{aligned}
& v_{1} \uparrow=r_{1} v_{1} \downarrow+\left(1-\mathrm{r}_{1}\right) v_{2} \uparrow \\
& v_{1}=-\frac{Z_{1}}{Z_{2}}\left(v_{2} \downarrow-v_{2} \uparrow\right)+v_{1}
\end{aligned}
$$

From Eqs. (12), (15) and (17), we gain

$$
v_{2} \downarrow=-r_{1} v_{2} \uparrow+\left(1+r_{1}\right) v_{1} \downarrow
$$

Figure 1 presents a classical stress wave propagated in an element of prestressed concrete bridge deck with variation of cross-sectional area. Assume that a compressive stress wave occurs at upper head due to impact. When this wave reaches depth $L_{1}$, since the cross-sectional area at $L_{1}$ is reduced and the reflection coefficient $r_{1}$ is positive value, the downward stress wave is tensile stress wave. When this wave reaches depth $L_{2}$, since the cross-sectional area at $L_{2}$ is recovered the originaly cross-sectional area and the reflection coefficient $r_{1}$ is negative value, the downward stress wave is compressive stress wave. As the state mentioned before, owing to $L_{3}$ is free end, the compressive wave reaches $L_{3}$ and reflects as the tensile wave. In the case of the prestressed concrete bridge deck, the occurred probability of the cracked cross-sectional area in a local region is very few.

Hence, the occurrence of tensile stress wave comes from the variation of cross-sectional area. Speaking generally, the variation of cross-sectional area influences the behavior of stress wave propagation. Based on Fig. 1, define the reflection coefficient [Middendrop and Van Brederode, 1983] as follows

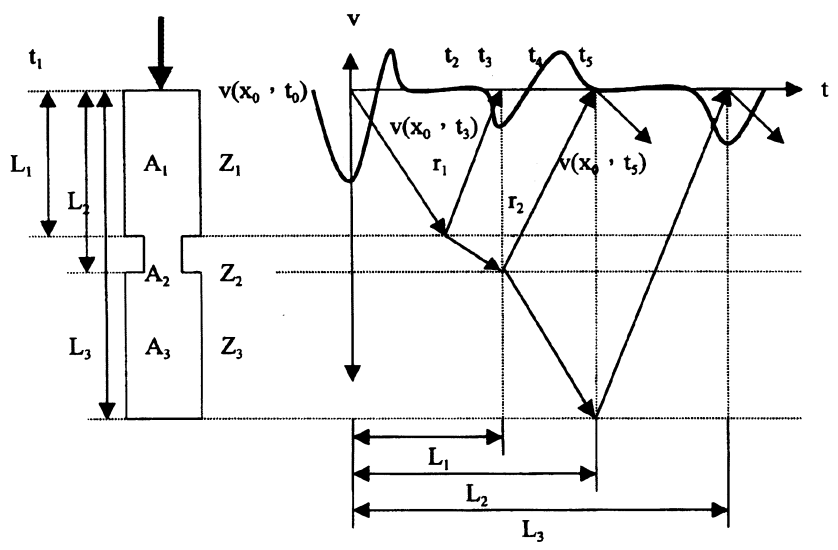

Fig. 1. Wave propagation in an element of prestressed concrete bridge deck with variation of cross-sectional area. 


$$
\begin{aligned}
& r_{1}=\frac{v\left(x_{0}, t_{3}\right)}{2 v\left(x_{0}, t_{0}\right)}=\frac{v_{1}}{2 v_{0}} \\
& r_{2}=\frac{v\left(x_{0}, t_{5}\right)}{2 v\left(x_{0}, t_{0}\right)\left(1-r_{1}^{2}\right)}=\frac{v_{2}}{2 v_{0}\left(1-r_{1}^{2}\right)}
\end{aligned}
$$

Thus, we obtain the ratio of discontinuous crosssectional area

$$
\frac{A_{3}}{A_{1}}=\frac{\left(1-r_{2}\right)\left(1-r_{1}\right)}{\left(1+r_{2}\right)\left(1+r_{1}\right)}
$$

Equation (21) represents that $\frac{A_{3}}{A_{1}}$ is a function of reflection coefficients of $r_{1}$ and $r_{2}$.

The aforementioned theory is elastic waves. If the viscosity of material was neglected, then the elastic waves can be referred as sonic waves [Bedford and Prumheller, 1994].

\section{Quality evaluation}

The major indisposition of the prestressed concrete bridge deck comes from indisposed outer loading. Therefore, we can not allowably make any mistake during the process of design, construction and grouted concrete. Otherwise, the bearing capacity of the prestressed concrete bridge deck has not enough. It is very obvious that the task of quality control is absolutely important for bringing into fully playing the expected function of the prestressed concrete bridge deck. At the current stage, the quality evaluation technique of the prestressed concrete bridge decks is not uniform. According to the report used the wave velocity method by Malhotra [1976] and Thomas [1981], we definitely know that the faster wave velocity propagating in the prestressed concrete bridge deck, the better concrete quality of it. The relationship between wave velocity and concrete condition is listed in Table 1 [Thomas, 1981]. Note that choose the suitable value of the wave velocity from Table 1 as a base of quality evaluation for the pretressed concrete bridge deck.

Another method of quality control is acquired many data from in-situ testing for doing analysis and establishing reference data. When a elastic or sonic wave propagates into a prestressed concrete bridge deck, if bridge deck has any crack, corrosion and variation of cross-sectional area then the damage position can be detected from the reflected wave form. Now, if $c$ and $E$ are constants, then we define

$$
\beta=\frac{Z_{2}}{Z_{1}}=\frac{A_{2}}{A_{1}}
$$

The integrity relationship between the value of $\beta$ and cross-sectional area of bridge deck is listed in Table 2 [Rausche and Goble, 1979]. Based on Eq. (22) and
Table 1. Relationship between wave velocity and concrete condition (Courtesy of Thomas, 1981)

\begin{tabular}{ll}
\hline Propagation velocity $(\mathrm{m} / \mathrm{sec})$ & Concrete condition \\
\hline$>4570$ & Excellent \\
$3660-4570$ & Good \\
$3050-3660$ & Not good \\
$2130-3050$ & Bad \\
$<2130$ & Very bad \\
\hline
\end{tabular}

Table 2. Value of $\beta$ related with the integrity of cross-sectional area of prestressed concrete deck (Courtesy of Rausche and Goble, 1979)

\begin{tabular}{ll}
\hline$\beta$ & Damage degree \\
\hline 1.0 & Nondamage \\
$0.8-1.0$ & Light damage \\
$0.6-0.8$ & Moderate damage \\
0.6 below & Severe damage \\
\hline
\end{tabular}

Table 2, we can predict the integrity of the prestressed concrete bridge deck.

\section{Basic concept of application}

According to the stress wave theory mentioned above, if the viscosity of tested material is assumed to be ignored then the elastic wave can be reduced as the sonic wave. Now, we use the sonic method to offer the concept way of application as described in the following:

(1) The analytical uncertainty of the prestresed concrete bridge deck due to material and aggregate size is higher than that of steel plate. We first present the concept way of application for steel cable in order to determine the serviceability of the sonic method for predicting the integrity of the prestressed concrete bridge deck. Fig. 2 shows a response of sonic testing to deck slab [Sugimoto, 1997]. The sensor is put at the position of symbol denoted by $\downarrow$. Use a small hammer to do an impact just near the sensor on the deck slab. At the same time, connect a cone jig with length $10 \mathrm{~cm}$ on the tip of accelerometer. The initial wave at the left side is thus occurred deformation. In advance, we obtain two end responses represented by symbol $\boldsymbol{\Delta}$. After the same response obtained three times, the abnormal wave can be removed. This wave is a fast wave transformed from the signal of accelerometer. Of course, although the accuracy is influenced by apparatus, the results obtained from repeated testing is still adopted [Joav, 1975]. However, the estimated length is really shorter than the actural length as shown in 


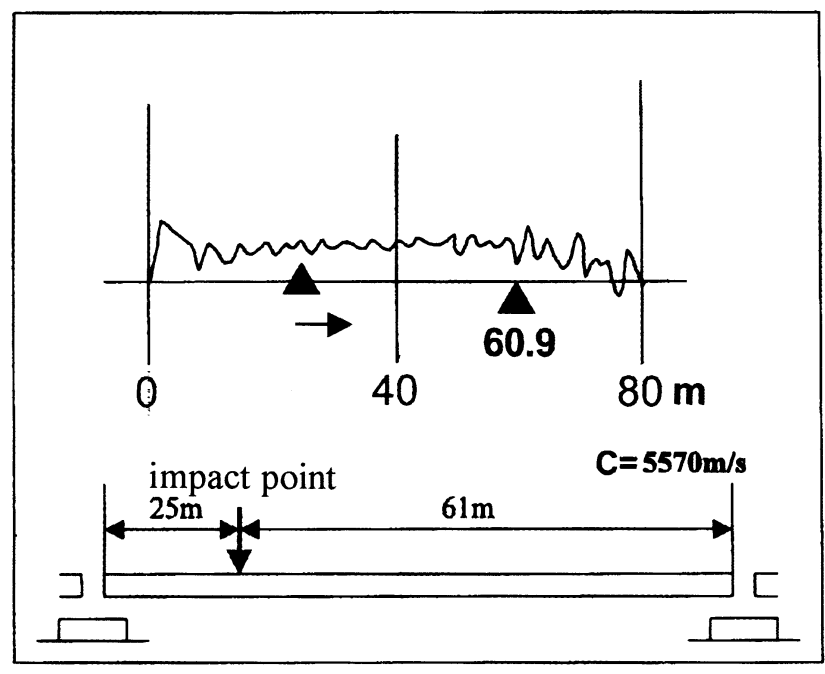

Fig. 2. Diagrammatic sketch of sonic method for testing steel cable. (Courtesy of Sugimoto, 1997)

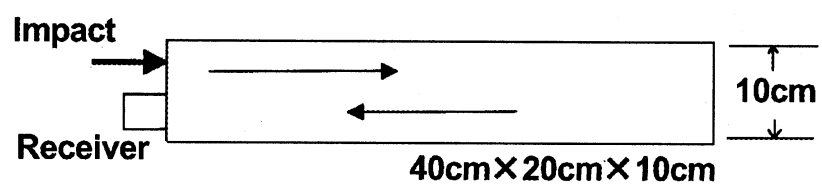

Fig. 3. Diagrammatic sketch of sonic method for testing prestressed concrete model.

Fig. 2. As a result, in this situation, the propagation velocity of steel cable is about $5570 \mathrm{~m} / \mathrm{s}$. At the same time, when impact on the steel cable for testing length with $61 \mathrm{~cm}$, the other response is reflected from the other side is detected at the point near $25 \mathrm{~cm}$. This measured result is satisfied. Therefore, we infer that the damage or integrity testing of bridge deck is serviceable.

(2) Figure 3 shows a diagrammatic sketch used the sonic method tested on the top of the prestressed concrete model. This tested model has length $40 \mathrm{~cm}$, width $20 \mathrm{~cm}$, thickness $10 \mathrm{~cm}$ and compressive strength with $280 \mathrm{~kg} / \mathrm{cm}^{2}$.

(3) Figure 4 denotes a diagrammatic sketch of the sonic method tested the prestressed concrete model with internal crack. Among the size, compressive strength of concrete and impact force are the same as Fig. 3. The symbol $\downarrow$ presents the impact point. When test a prestressed concrete bridge deck, chosen a suitable testing point is very important. Since the internal crack in the prestressed concrete bridge deck is very small, the damage to be predicted is very difficult. Hence, for choice a testing point on the bridge deck is serviceable.

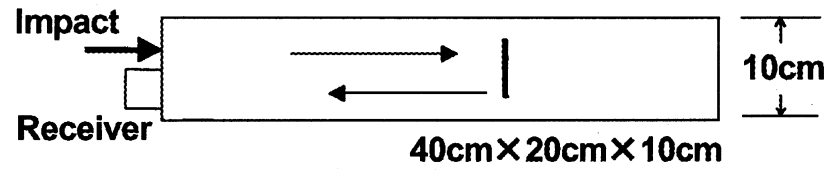

Fig. 4. Diagrammatic sketch of sonic method for testing prestressed concrete model with internal crack.

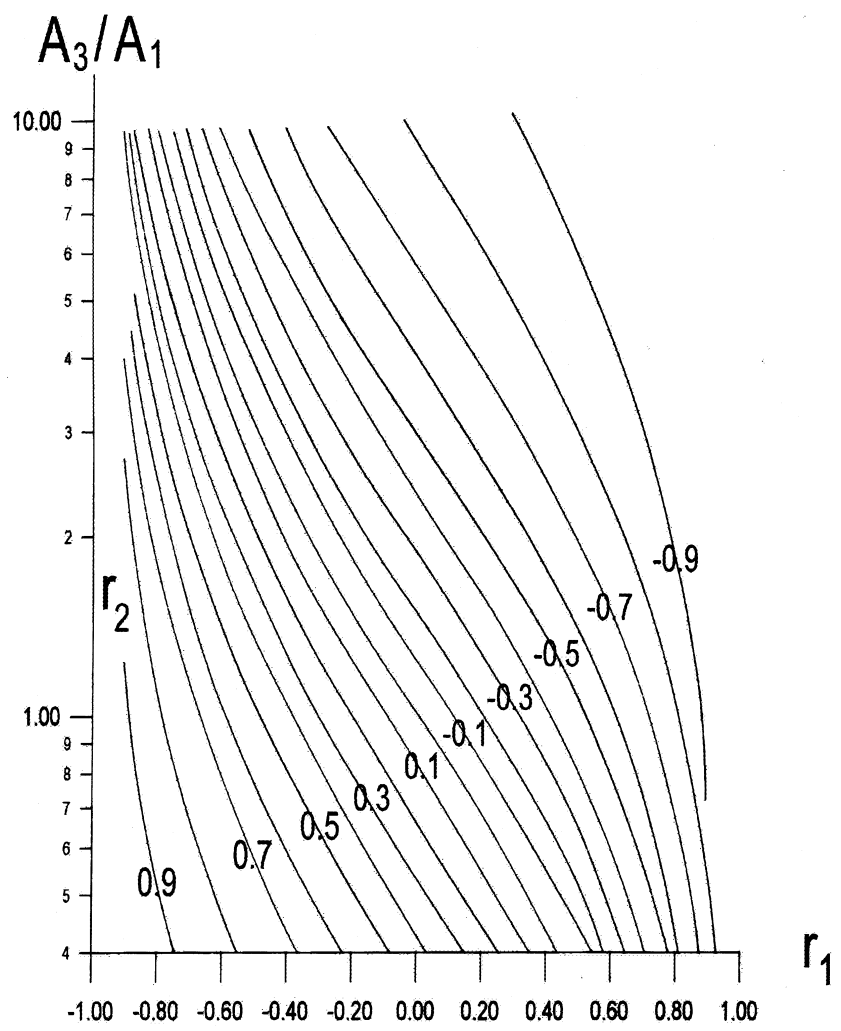

Fig. 5. Relationship between transmission coefficient and ratio of crosssectional areas.

(4) Based on the calculation of Eqs. (19), (20) and (21), we can obtain cross-sectional area ratio $\frac{A_{3}}{A_{1}}$ and reflection coefficients $r_{1}$ and $r_{2}$. Fig. 5 shows the relationships among $\frac{A_{3}}{A_{1}}, r_{1}$ and $r_{2}$. When a prestressed concrete bridge deck is carried out integrity evaluation, using Fig. 5 can be reduced the troublesome and tedious calculation.

If we want to do a quality testing for the prestressed steel tendon in the prestressed concrete bridge deck, the transmitter and receiver are connected on the prestressed tendon at the end of bridge deck as shown in Fig. 6. Propose that the prestressed tendon occurs failure due to corrsion damage, The reflection time $t_{x}$ can be analyzed from the sonic wave obtained from 

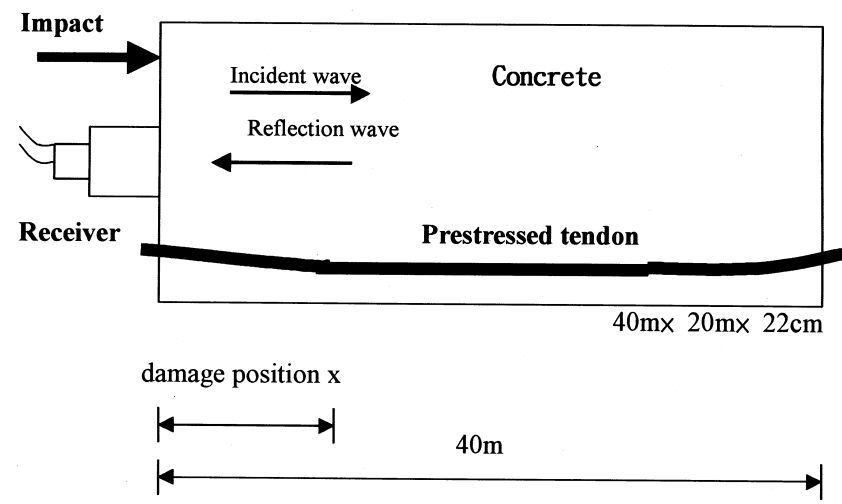

(a)

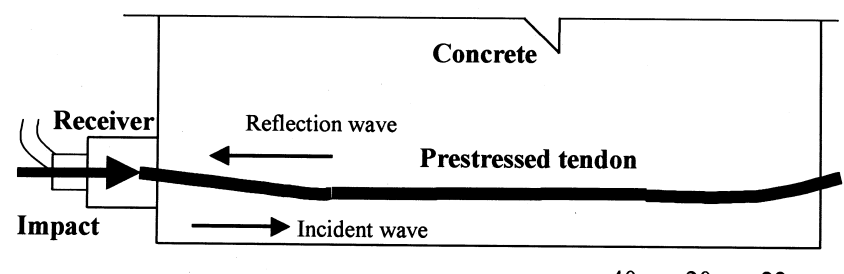

$40 \mathrm{~m} \times 20 \mathrm{~m} \times 22 \mathrm{~cm}$

damage position $\mathrm{x}$

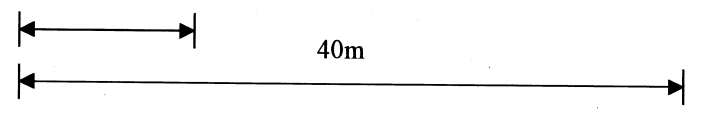

(b)

Fig. 6. Diagrammatic sketch of sonic method tested for steel tendon in prestressed concrete bridge deck.

receiver. Thus, the damage position $\mathrm{x}$ can be calculated by the formula

$$
t_{x}=\frac{2 x}{c}
$$

Considering the Fig. 5, if the ratio of cross-sectional area is below the range of $\frac{A_{3}}{A_{1}}=1$, then the warning significance is the same as the value of $\beta$ as shown in Table 2. For example, if the value of $\frac{A_{3}}{A_{1}}=$ 0.5 , then the prestressed tendon is in the state of severe damage. In other words, when a prestressed tendon has two value of $\beta_{1}=\frac{A_{2}}{A_{1}}$ and $\beta_{2}=\frac{A_{3}}{A_{2}}$ due to two discontinuous cross-sectional area, we have $\beta_{1} \beta_{2}=\frac{A_{3}}{A_{1}}$. The advantage of using Fig. 5 is in fact not only analyzed the ratio of cross-sectional area of the prestressed concrete bridge deck but also divided the region of damage type of the prestressed concrete bridge deck. Based on Fig. 5 , nine kinds of damage type occurrsed possibly in the prestressed concrete bridge deck are drawn in Fig. 7.

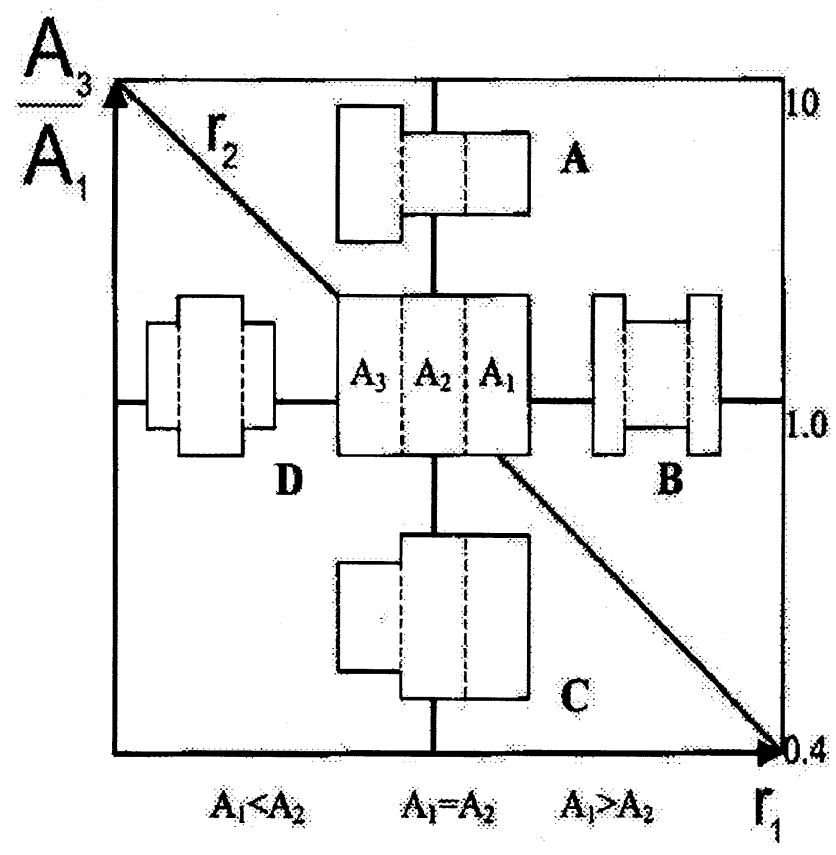

(a)

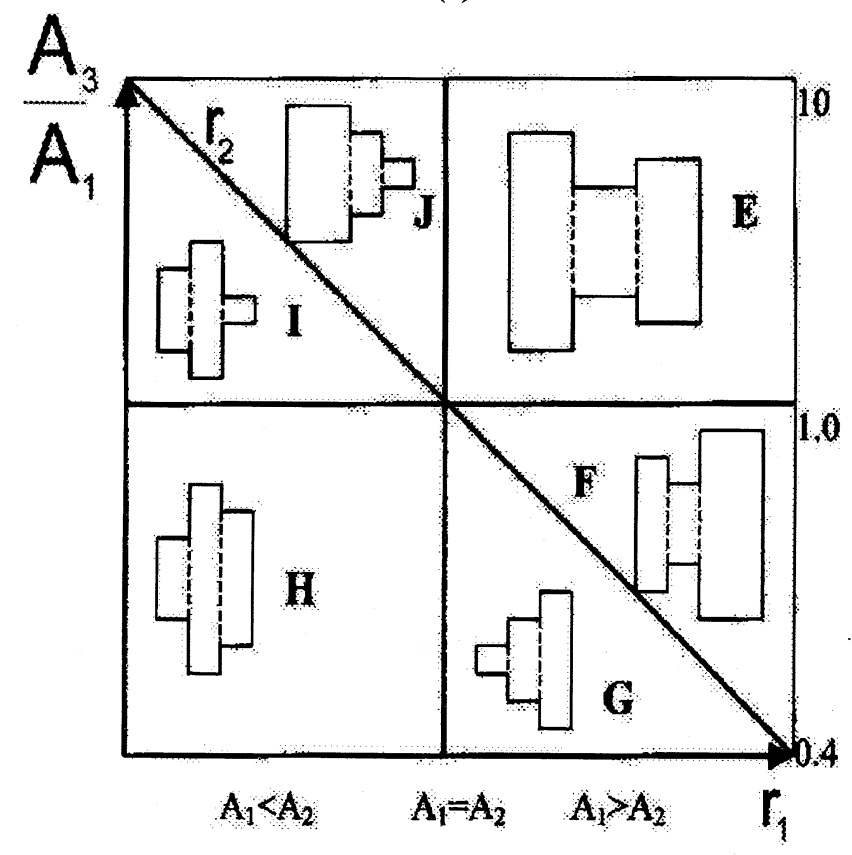

(b)

Fig. 7. Analytical diagram of damage type of prestressed concrete bridge deck.

The two analytical diagram of damage type of the prestressed concrete bridge deck have two intersectional lines of $\frac{A_{3}}{A_{1}}=1$ and $A_{1}=A_{2}$. Thus, we can divide the analytical diagram into some regions of damage 
type as shown in Fig. 7. In the most of integrity testing, the condition of $A_{1}=A_{2}=A_{3}$ is very few. If compose the cross-sectional areas among $A_{1}, A_{2}$ and $A_{3}$, the damage type of the prestressed concrete type can be easily found from Fig. 7. Similarly, if any two values among $A_{1}, A_{2}$ and $A_{3}$, are equal, the damage type of the prestressed concrete type are also found.

\section{CONCLUSIONS}

This study provided the concept way of application for predicting integrity of existing prestressed concrete bridge deck using the sonic method. The theory of sonic method was derived from one-dimensional wave equation based on that the viscosity of material was ignored. The advantage of the sonic method may be portable and simple in usage and analysis. Both the damage position and damage type may be really predicted by using the sonic method. The predicted results may be not only reliable but also accurate. However, the high accuracy from visualized method associated with microcomputer suggest further research with large groups of civil engineers and scholars. As the future research, further examination of the above sonic method and enhancement of precision are required.

\section{REFERENCES}

1. Akasrii, T., "Studies on Nondestructive Testing of Concrete," Proceeding of JSCE, Vol. 8. pp. 1-22 (1998).

2. Bedford, A. and Prumheller, D.S., "Introduction to Elastic Wave Propagation,' John Wiley \& Sons, New York, (1994).

3. Hong, D.H., "Corrosion and Protection of Steel in Concrete," Chinese Railway Press, Beijing, pp. 214215.(1998) (in Chinese).

4. Han, B.W. and Wang, D.G., "Application of Sonic Tomography in the Integrity Testing of Concrete Piles," Barends, F.B.J. Ed. The Hange, The Netherlands, Balkema, Rotterdam, pp. 231-234 (1992).

5. Joav, S., "Caisson Evaluation by Stress Wave Propagation Method," Journal of the Geotechnical Engineering Division, ASCE, Vol. 101, No. GT4, pp. 361-378 (1975).

6. Jones, D.A., "Principles and Prevention of Corrosion," Second Edition, Prentice Hall, Inc., NJ, (1996).

7. Kreyszig, E., "Advanced Engineering Mathematics," Eighth Edition, John Wiley \& Sons, New York, (1999).

8. Liang, M.T., "Condition Monitoring of Piled Foundation" Ph.D. Thesis, University of Aberdeen, Scotland, United Kingdom, pp. 16-24, June (1986).

9. Middendrop, P. and Van Brederode, P., "A Field Moni- toring Technique for the Integrity Testing of Foundation Piles," International Symposium on Field Measurements in Geomechanics, Zurich, pp. 493-502 (1983).

10. Malhotra, V.M., "Testing Hardened Concrete: Nondestructive Methods," Iowa State University Press, Ames, Iowa, and American Concrete Institute, Detroit, Michigan, pp. 87 (1976).

11. Rausche, F. and Goble, G.G., "Determination of Pile Damage by Top Measurements," Behavior of Deep Foundations, ASTM STP 670, pp. 500-506 (1979).

12. Sugimoto, M., "Bridge Diagosis by Shock and Vibration Method," Safety \& NDT'95' International Workshop KSNT, pp. 25-38 (1995).

13. Sugimoto, M., "Trial of Prestressed Concrete Cable Testing by Sonic Integrity Tester," Fourth Far East Conference on NDT (FENDT'97), Cheju-do, Korea, Oct. 8-11, pp. 451-460 (1997).

14. Treadaway, K., "Corrosion Period, In: Corrosion of Steel in Concrete," (Edited by P. Schiessl), Chapman and Hall, London, (1988).

15. Thomas, M., "Drilled-Shaft Integrity by Wave Propagation Method,' Journal of the Geotechnical Engineering Division, ASCE, Vol. 107, No. GT10, pp. 1327-1344 (1981).

16. Zhao, G.F., "Reliability Theory and Its Application for Engineering Structures," Dalian University of Technology Press, Dalian, China, pp. 302-303 (1996) (in Chinese).

\section{音波法檢測既有預力混凝土橋面版 之完整性}

梁 明德吴 伋

國立台灣海洋大學河海工程學系

摘 要

本文主要目的係提供採用音波法非破壞檢測預 力混凝土橋面版之完整性的概念性方式。採用一維波 動方程式結合初始條件作爲控制方程式, 以傅立葉轉 換求控制方程式之解析解, 由此解析解推導位移、速 度、力量及應力波等波傳公式, 若忽略混凝土材料内 之秥滞性, 則應力波就可視爲音波, 利用音波的波傳 公式即可預测既有預力混凝土橋面版之完整性, 預测 結果可供維修及補強之依據, 研究結果顯示音波法或 許能夠檢测預力混凝土橋面版的裂縫位置, 及預力鋼 鍵腐蝕或斷裂的位置, 音波法之主要優點也許在於不 僅攜带方便且使用簡捷, 建議實驗應證。 